\title{
Actin pushes in bizarre places
}

ewis Tilney has always had a gift for looking for biology in strange places. His publishing history, he says, reads like a "Rogue's gallery" of plants, fungi, parasites, and plenty of unusual invertebrate creatures. "It's just ridiculous, and nowadays I couldn't get away with it." His colleagues say it is part of his genius to look in unusual systems to answer fundamental biology questions, but Tilney shrugs off that idea.

"I have the attention span of a five-year-old," he says. "It's always wonderful to start a new project that's curious and interesting. Then something else attracts my attention and I move on-it's a lack of commitment on my part." So it's no surprise that one of Tilney's major contributions-proposing actin polymerization as a method of force generation within the cell-came through two landmark papers characterizing unorthodox systems: the acrosomal reaction in both starfish and sea cucumber sperm, and the cell-to-cell motility of the Listeria monocytogenes bacterium.

In the late 1960s, cytoplasmic actin that was not bundled into a contractile unit with myosin was just beginning to be recognized. At a lecture at Woods Hole Oceanographic Institute, Tilney heard Jean Dan describe the amazing acrosomal reaction of starfish sperm, which in seven seconds shoots out a process that is 45 times the length of the sperm cell. In Dan's fuzzy pictures, Tilney could just make out some intracellular filaments inside the process. Could cytoplasmic actin be responsible for this fantastic reaction?

Using a glutaraldehyde and osmium tetroxide "mixed fix" that stabilized actin filaments, Tilney and his colleagues captured stunning pictures of the acrosomal process reaction with a clear bundle of filaments filling the process (Tilney et al., 1973). They identified the major protein in the acrosomal process as actin both by binding myosin in situ and by SDS gel electrophoresis. Since $80 \%$ of the actin was a monomer before the reaction and appeared amorphous in the images, Tilney reasoned that the only way to generate the process so quickly would be actin polymerization. "It was pretty obvious it had to be assembled, but I got a lot of heat for this," he says. "The key question was, how can you push and polymerize at the same time?"

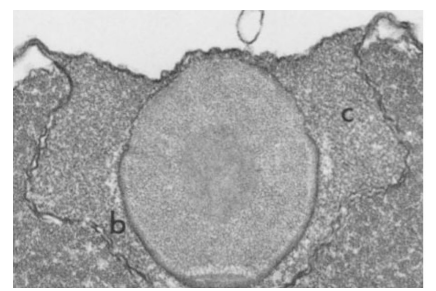

Actin drives the acrosomal reaction (left to right).

quickly: "I had worked out the tissue culture model of infection and the system was ripe to analyze. Tilney had the right methods to look at actin. We submitted the paper by Christmas."

The collaboration demonstrated that Listeria, once inside a cell, acquired a "comet tail" of actin. It moved with the comet to the cell surface and into a cell extension that is eventually engulfed by a neighboring cell (Tilney and Portnoy, 1989). Tilney wrote, "thus, this insidious beast has managed to multiply and spread cell-to-cell without leaving the cytoplasm of its host." (Portnoy had objected to the original wording, which included a description of the beast's "Machiavellian deviousness.")

The work led others to discover actin nucleation proteins such as the bacterial ActA protein (Domann et al., 1992; Kocks et al., 1992) and the Arp2/3 complex (Welch et al.,

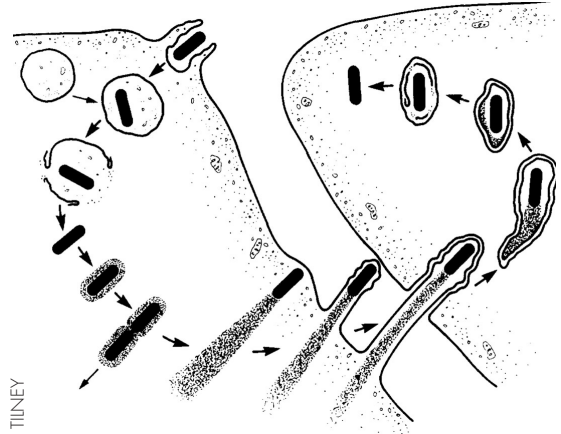

Actin-powered rocketing by Listeria gets it into adjacent cells. 1997). The system could be reconstituted in vitro (Theriot et al., 1994; Loisel et al., 1999), and without myosin, so it clinched the idea that polymerization was generating the motility of the bugs. The force-by-elongation mystery would eventually be answered by a mathematical demonstration that Brownian motion could account for actin elongation pushing a membrane forward (Mogilner and Oster, 1996).

Matt Welch, who purified the actin nucleation complex, says the 1989 Listeria paper, "was really the culmination of this whole field of actin polymerization as a mode of motility. You didn't need myosin to move these bacteria around and people made extremely good use of that system to show that what Tilney was saying in the 1973 [acrosomal process] paper

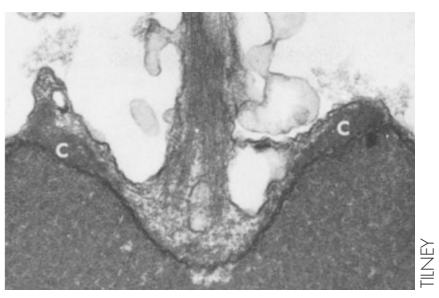
was really true."

Mark Mooseker, a coauthor on that first acrosome paper, says Tilney, still using a 45-yr-old Philips 200 scope, remains one of the best electron microscopists in the field. "He is an absolute hero of mine and his impact is just huge." Most recently, says Tilney, his studies have "drifted again" to look at a parasitic nematode: "a very curious beast with a sophisticated external gut-it's both entertaining and disgusting." We would expect no less. JCB

Domann, E., et al. 1992. EMBO J. 11:1981-1990.

Kocks, C., et al. 1992. Cell. 68:521-531.

Loisel, T.P., et al. 1999. Nature. 401:613-616. Mogilner, A., and G. Oster. 1996. Biophys. J. 71:3030-3045

Tilney, L.G., et al. 1973. J. Cell Biol. 59:109-126.

Tilney, L.G., and D.A. Portnoy. 1989. J. Cell Biol. 109:1597-1608.

Theriot, J.A., et al. 1994. Cell. 76:505-517.

Welch, M.D., et al. 1997. Nature. 385:265-269. two "hit it off scientifically," Portnoy recalls, and the work went 